\title{
Dietary acculturation of Hispanic immigrants in Mississippi
}

\author{
Virginia B. Gray, PhD, RD, (1) Jeralynn S. Cossman, PhD, (2) Wanda L. Dodson, PhD, FADA, ${ }^{(3)}$ \\ Sylvia H. Byrd, PhD, RD(4)
}

\section{Gray VB, Cossman JS, Dodson WL, Byrd SH. Dietary acculturation of Hispanic immigrants in Mississippi. Salud Publica Mex 2005;47;35I-360.}

\begin{abstract}
Objective. Assisting Hispanic immigrants in making culturally acceptable food choices may affect their health for generations. As a relatively new enclave of Hispanics, Scott County, Mississippi, was chosen to study dietary acculturation and health concerns of immigrants. Material and Methods. The research method consisted of interviews with community representatives $(N=I I)$, a focus group $(N=6)$, and interviews with Hispanic immigrants $(\mathrm{N}=18)$. Results. Community representatives mentioned availability influenced immigrants' food choices and suggested promoting cultural awareness and offering nutrition classes on local ingredients. Food cost, health concepts, food selection, and eating habits of children were salient themes from the focus group and interviews with Hispanics. Hispanic participants mentioned long work hours affect food selection and that US produce lacks freshness and flavor. Conclusions. Results indicate that an intervention must be formulated that preserves healthful dietary practices and minimizes the negative health aspects of acculturation to the "American diet."
\end{abstract}

Key words: diet; culture; transients and migrants; Hispanic Americans; Mississippi, United States

\author{
Gray VB, Cossman JS, Dodson WL, Byrd SH. \\ Aculturación alimentaria \\ de inmigrantes hispanos en Mississippi. \\ Salud Publica Mex 2005;47;35 I-360.
}

\section{Resumen}

Objetivo. Ayudar a inmigrantes hispanos en la elección de una dieta culturalmente aceptable puede incidir sobre su salud por generaciones. Para estudiar la relación entre aculturación alimentaria y salud en los inmigrantes, se escogió Scott County, Mississippi, un enclave relativamente nuevo de inmigrantes hispanos en Estados Unidos de América (EUA). Material y métodos. El método de investigación consistió en entrevistas con representantes de la comunidad $(N=\mid \mathrm{I})$, un grupo focal $(N=6)$ e inmigrantes hispanos $(\mathrm{N}=18)$. Resultados. Representantes de la comunidad mencionaron que lo que influye en la elección de sus alimentos es la disponibilidad de éstos; asimismo sugirieron la organización de actividades para conocer diferentes culturas, al igual que clases de nutrición para aprender cómo utilizar ingredientes locales. Cinco fueron los temas más relevantes que se identificaron durante las entrevistas con los inmigrantes y el grupo focal: el precio de la comida, ideas sobre la salud, factores que influyen en la selección de la comida y la nutrición de los niños inmigrantes. Los participantes hispanos mencionaron que las jornadas de trabajo tan largas afectan la selección de la comida y que los productos del campo en EUA no son frescos ni tienen sabor. Conclusiones. Los resultados indican que hace falta una intervención que ayude a preservar prácticas alimentarias saludables y que minimice los aspectos negativos de la aculturación por la dieta predominante en EUA.

Palabras clave: dieta; cultura; transeúntes y migrantes; hispanoamericanos; Mississippi, Estados Unidos

(I) School Based Initiatives, FoodChange, New York, USA

(2) Department of Sociology, Anthropology and Social Work and Social Science Research Center, Mississippi State University, USA

(3) School of Human Sciences, Mississippi State University, USA

(4) Department of Food Science, Nutrition, and Health Promotion, Mississippi State University, USA 
A cculturation $^{*, 1}$ of US immigrants may affect dietary habits and nutrition status. Both new and former food habits may have health implications for immigrants and their offspring. Research indicates that cultural changes are associated with a positive influence on nutrition for some and negative effects for others. Howeverlittle research has been conducted to assess the effect of acculturation on Hispanics' nutrition, ${ }^{2}$ particularly in rural areas. Research also shows a strong correlation between acculturation and obesity. ${ }^{3}$ As obesity is directly related to diet and physical activity and is linked to many health risks, study of the dietary changes that accompany integration into the US society and factors leading to these changes among Hispanics is needed.

Food choices of newly-arrived immigrants are affected by availability of food, differences in schedules, cultural differences, and other factors (e.g., the community structure). Integration into a new culture involves great changes for immigrants, including adjustments to differences in language, values, the concept of time, family ideology, and food habits. ${ }^{4}$ Hispanic immigrants to the US are varied in cultural, social, and economic backgrounds; the immigrant's country of origin, the city of relocation in the US, and the financial situation of the immigrant are among the factors that affect whether changes in food habits will be profound or minimal. Common ingredients, such as spices and condiments, in the diets of certain cultural groups may be scarce or inaccessible in the rural US. Additionally, the cost of certain foods may affect purchasing decisions. Thus, dietary acculturation is sure to accompany social integration in the US.

In the year 2000, there were 12.8 million foreign born Hispanics in the US. ${ }^{5}$ Although traditionally concentrated in metropolitan areas of certain states, ${ }^{5}$ other states have begun to see an influx of Hispanic immigrants. The Hispanic population in the Southern states almost tripled (to more than 1.9 million) between 1990 and 2000, ${ }^{6}$ resulting in social, demographic, and cultural changes for the resident population and the immigrants. In Mississippi, the Hispanic population increased from 15931 in 1990 to 39569 in 2000. ${ }^{7}$ Hispanic immigrants to the rural South are likely to have a different experience than those who immigrate to other areas; ${ }^{8}$ states where immigrants have traditionally settled provide more established resources to help

\footnotetext{
* Acculturation has been defined as adaptation to a new major society that results when people of one ethnicity move to an area with different cultural features. Reference 1 .
}

newcomers ${ }^{9}$ whereas the rural South has fewer resources to aid immigrants in adjusting to a new cultural environment.

Dietary acculturation may affect risk for chronic disease. Research shows Hispanics experience higher rates of certain nutrition-related chronic diseases (e.g., obesity, diabetes) than Caucasians. ${ }^{10}$ For example, research shows a generational correlation in obesity incidence in the US among Hispanics, with second generation immigrants being more than twice as likely to be obese as first generation immigrants to the US. ${ }^{3}$ Additionally, uninsurance and poor access to care are important issues for Hispanics in the US. ${ }^{11}$ Though trends have been noted related to health risks of Hispanic immigrants in the US, little research has examined the effect of dietary acculturation on such patterns.

Hispanics are experiencing rapid dietary acculturation, resulting in both positive and negative health consequences. The traditional diet of many Hispanics is healthy, including many complex carbohydrates and vegetables. ${ }^{2,12}$ However, Hispanics in the US are eating fewer complex carbohydrates and more simple sugars, fat, white sliced bread, vegetable salad, mayonnaise, flour tortillas, sweetened beverages, snacks, sweets, and meats. ${ }^{2,12,13}$ With increased length of stay in the US, the diet of Hispanics resembles more closely that of the non-Hispanic white, ${ }^{2}$ and children of immigrants often begin to prefer "American foods." Investigation of food consumption patterns, how they change, and what affects the process of change is essential for developing educational programs that effectively treat and prevent overweight and other chronic conditions. ${ }^{14}$ Public and private institutions are faced with necessary adaptations to aid newcomers' incorporation. Areas with few Hispanics may not be prepared to handle these challenges. ${ }^{7}$

\section{Objectives}

Assisting immigrants in making healthy food choices in a new area may affect their nutritional status. Understanding their native food habits and changes since immigration allows for reinforcement of the positive dietary decisions as well as education in areas that could use improvement. It is also important to assess the availability and use of services and programs for immigrants in a community. The ultimate goals of the current study (henceforth referenced as the Scott County study) were to identify barriers to participation in community nutrition programs, to identify barriers to nutritious eating practices, and to characterize the nature of dietary changes related to immigration to the US. 


\section{Material and Methods}

\section{Research setting}

Scott County, Mississippi, has the highest proportion of Hispanics (Hispanics comprised 5.8\% of the population 2000) in the state. Approximately $1 \%$ of the Hispanic population was surveyed in the current study. ${ }^{15}$ The high proportion of Hispanics in the area relative to the rest of the state (1.39\%) is largely due to twenty years of recruitment of Hispanic labor by the poultry industry. In order to establish rapport in the community, four home visits were made with a community center representative to assess the formative research potential with Hispanics in the community. The community center, operated by a religious order, served as the primary point of contact for the study. During the home visits, concerns of the individuals with respect to dietary changes since immigration were solicited. Individuals expressed interest in sharing experiences about foods and provided suggestions related to the study objectives.

\section{Subjects}

A convenience sample was used in all phases of the study, with participants recruited from a list provided by a community worker at the center. During interviews with community representatives, several participants suggested further interviews with representatives they knew to be involved with Hispanics in the community. Focus group participants and interviewees were identified from a list of 23 families provided by the community center; two additional contacts were made in the community during the interview process by referral.

\section{Instruments and procedures}

Interviews were chosen as the means of data collection, as the in-depth nature of this technique provides the most information about knowledge and attitudes from a specific group of people. ${ }^{16}$ Research was conducted in five phases in an adaptation of the Concern Report Method. ${ }^{17}$ This method was chosen to identify community assets and concerns as perceived by both community representatives and Hispanic immigrants, and to allow for the study's results to be shared with community members and immigrants at the end of the study. Phase 1 consisted of interviews with 11 com- munity representatives* to identify community services offered for Hispanics, health concerns of Hispanic immigrants as perceived by community leaders, and community organizations' joint efforts to work together in support of Hispanics. Interviews were audio recorded $(n=6)$ with consent of participants, and written notes from interviews were used for the analyses. These data, in addition to existing literature related to acculturation of Hispanic immigrants in the US, ${ }^{2,12-14,18-20}$ were used to prepare questions for interviews with Hispanic immigrants.

Phase 2 consisted of a focus group ( $N=6)$ using the cognitive think aloud method ${ }^{21}$ to review content of questions proposed for use in Phase 3 of the study. The group assessed the comprehension and cultural relevancy of the questions' content, identified omitted concerns, provided additional suggestions, and responded to many of the questions, allowing for comparison with responses of Phase 3 participants. The focus group was conducted in Spanish by the primary investigator who is bilingual, and responses were translated after the session by listening to an audio recording that was made of the discussion.

Phase 3 consisted of interviews with female Hispanics $(N=18)$, who typically purchase and prepare food in traditional Hispanic families, using open-ended questions to elicit personal reflection on native food habits in comparison to US food habits. Phase 3 interviews were also recorded by audiotape $(n=11)$ with interviewee consent. Interviews took place either in the homes of interviewees or at the community center. Responses were annotated during interviews, and responses were verified by reviewing recordings. Four interviews were conducted in English, and 14 in Spanish. The primary investigator translated interviews conducted in Spanish. Questions used in Phase 3 probed themes such as food purchasing and prices, availability of ingredients, meal patterns, influences on food choices, the meaning of healthy eating, perceived differences in food between the country of origin and the US, preparation methods, food preferences of children, American foods avoided, and favorite restaurants.

\footnotetext{
* Respondents included a pharmacist, an elected official, a translator, a dietitian, a representative from the Department of Human Services, a business owner, a pastor, an employee of a religious organization, a school employee, a manager company that employs many Hispanics, and an employee at a community center.
} 
Content analysis ${ }^{22}$ (CA) was used to analyze interview responses (Phase 4). The data were examined for categories, key words, and themes. ${ }^{22}$ Lists were made of the responses to each question, similar responses were grouped, and data were analyzed for trends. Questions addressing similar ideas were considered in groups. To aid in data interpretation, a meeting with two Hispanics involved in more than one phase of the project was held to discuss validity of data, trends observed, procedures, and suggestions. These individuals were presented with tables and phrases grouped by themes from the interviews, and they were asked to review and discuss the data.

Finally, a report was provided to study participants (Phase 5), including an abstract, a summary of responses, an interpretation of results, and suggestions for action (in Spanish and English). Participants were invited to a dinner meeting at which time the results were shared both verbally and in written form. Study participants not in attendance were provided with a copy of the results by mail.

Approval to conduct this study was obtained by the Institutional Review Board at Mississippi State University. Written informed consent was obtained from community leaders who participated in the project. Oral informed consent was obtained from immigrant participants in order to protect their privacy and identity, as some were not in the US on legal terms. A written copy of the oral agreement was provided to all participants.

\section{Results}

The responses obtained during Phases 1-3 describe the services provided in the county, the perspectives of community representatives about Hispanics in their area, and the experiences of Hispanics with regard to the effect of acculturation on dietary habits.

\section{Phase I: Interviews with community representatives}

Seven of the interviewees were extensively involved with Hispanics in the county; three had some involvement; and one had very little involvement (an elected official). Community representatives identified services provided in the community, including health-related services, weekly aerobics classes, nutrition education, translation services at the health department, English classes, religious services/spiritual help, food banks, tutoring in schools, Hispanic foods in grocery stores, pharmaceutical information in Spanish, and a complimentary weekly Spanish newspaper. Representatives also identified organizations that support newly-arrived immigrants, including: churches, the community center, businesses such as grocery stores, the Spanish newspaper, the Department of Health and Human Services, a university Extension Service, a sliding scale medical clinic, a pharmacy, the mayor (who tries to involve Hispanic youth in soccer teams), and the State Department of Health. Several participants mentioned the community center, and churches (particularly the Catholic Church), as providing important services. One community leader made the following comment: "When Hispanics first came, the community was caught unprepared. No one is just seeking to help. Some have been forced into helping, others have seen they can make money by serving Hispanics, but they are not motivated by desire to help."

Six representatives provided examples of cooperation between various community agencies in supporting immigrants, such as a bank that paid for several employees to take Spanish lessons, a cardiovascular risk research project, and parenting education classes sponsored by a religious charity and the Department of Health and Human Services. One interviewee mentioned that a previous effort for collaboration between agencies was discontinued due to lack of regular participation. During the interviews, it was mentioned that a chicken processing plant that employs many Hispanic immigrants provided social services when the first immigrants were recruited to the area about 20 years ago. Schools had requested funds for "dealing with" non-English speaking children since their parents had been recruited to the area to work at the plant, but these services are no longer available; it was reported that the company claims to lack funding to support social services for employees.

Community representatives were asked to provide suggestions for meeting the nutrition needs of immigrants and for helping newcomers become accustomed to a new food supply. Many recognized the need for promoting cultural understanding in the community through addressing the language barrier, learning about the culture of the newcomers, and raising community awareness about immigrant issues. Community representatives also suggested educational efforts related to food/nutrition and cultural diversity, suggesting a perception that Hispanic immigrants need nutrition education.

Community representatives identified factors they suppose influence food choices of Hispanics; availability of foods was mentioned most often. One mentioned work as a factor and other responses included unfamiliarity with American products, lack of knowledge about cooking, availability of fast food (especially for 
single male immigrants), cost of food, influence of children's food preferences, purchase of familiar foods, and ability to afford more meat in the US than in their home countries.

Interviewees expressed physical, social, and emotional concerns regarding Hispanics' health. Physical concerns included low compliance with medical advice, lack of balanced diet and physical activity, risk for obesity, high blood pressure, diabetes, poor housing conditions, and low access to health care. Interviewees expressed a variety of emotional and social concerns. It was mentioned that some immigrants feel lost, displaced and afraid (especially the undocumented), perhaps motivating alcohol use; many feel lonely, having considered financial opportunities in coming here but not all of the hardships associated with the move. The stress of distance from family, mental health concerns, fear of deportation, inability to procure a bank account (risk of robbery and violence due to keeping cash at home), lack of entertainment, lack of English-speaking ability, and lack of understanding of the health consequences of certain behaviors, such as smoking and weight gain were mentioned. It was reported that the "Hispanic" food sections in local grocery stores has increased since Hispanics have arrived in Scott County, and if they continue to stay in the area, it was believed that more of "their" foods would be stocked. At the time of the interview, one particular store had four 8-foot long sections stocked with "Hispanic" products.

\section{Phase 2: Focus group}

The focus group participants ( $N=6$ ) reviewed questions for Phase 3 of the project content and responded to the questions as they reviewed them. Participants confirmed that the interview questions were appropriate for the interviews and provided suggestions for improvement. A question was added to address participants' concern about the eating habits of immigrant children in the US, especially at school. Focus group participants' responses are reported alongside Phase 3 results to allow for comparison.

\section{Phase 3: Interviews with Hispanic immi- grants}

From a list of 23 families, 18 interviews were completed with Hispanics living in the county, 17 of whom had immigrated from outside of the US and one of Mexican descent who had moved to Mississippi from Texas. Although it is often perceived that Hispanic immigrants in the rural South have come from Mexico, participants in the Scott County study immigrated from a variety of countries, including Mexico $(n=4)$, Puerto Rico $(n=1)$, El Salvador $(n=1)$, Chile $(n=3)$, Peru $(n=2)$, Cuba $(n=1)$, Honduras $(n=1)$, Nicaragua $(n=2)$, and Argentina $(n=2)$. All participants were female and ranged in age from 23 to 78 years $(M=39.8 \pm 13.2)$. Educational attainment of participants ranged from 5 months to 20 years of schooling $(M=12.1 \pm 4.6)$. Participants reported the number of years they have lived in the US, ranging from one year to 31 years $(M=11.2 \pm$ 8.6 years). Most participants $(\mathrm{n}=10)$ lived in households of three to four people; the number of people living in each household ranged from 2 to 7.

The interview consisted of 27 questions developed from outcomes of Phase 1 and Phase 2 of the study. It was perceived that participants intend to remain permanently in Scott County, in contrast with migrant Hispanic farm workers who often move around the States and may return home. Analysis of the results produced five salient themes: (1) purchase and preparation of foods, (2) ideas about healthy nutrition, (3) influences of food choice in the US, (4) perceived effects of school food on nutrition of children, and (5) differences in frequencies of consumption of foods eaten in their native country and the consumption in the US. Each of these themes is presented and summarized in Table I. Selected quotes related to the first four themes are provided in Table II. Interview questions were open ended, and therefore themes presented in Tables I and II reflect the perspectives of interviewees. Table III describes changes in consumption patterns of individual foods (theme 5).

Meal patterns. Participants were asked several questions related to meal patterns, such as the time of day when the largest meal is consumed, the number of meals eaten per day, and the family's favorite restaurant. Most participants usually ate two to three times per day, and most referred to the meals as breakfast, lunch, and dinner. Dislike of leftovers was expressed by many, though many also claimed to save them to serve at the next meal or to eat for lunch the next day. Others mentioned feeding leftovers to the dog, throwing them out, or planning to prepare only what is needed. The Chinese restaurant was the favorite of $33 \%$ of participants, and the Mexican restaurant was the favorite of $17 \%$ of participants. Other restaurants were also mentioned. Focus group participants claimed there were fast food restaurants in their home countries; however, people in their home countries went rarely; they report buying fast food much more frequently here. 
Table I

Phase 3: Interview responses related to cost and PURChase/Preparation of Foods, food supply,

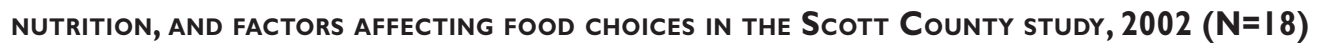

Number of participants* Percent

Comments relating to cost of food:

Food is more expensive in the US

Some things are more/some are less

Salary/cost of living are so different that cost cannot be compared

$\begin{array}{ll}8 & 44 \\ 2 & 11 \\ 5 & 28\end{array}$

Comments relating to purchase and preparation of food:

Female purchases food

Couple goes to purchase food

$10 \quad 56$

Female decides what to buy

Couple decides what to buy

Kids influence choices of food purchases

Cooking methods are similar (appliances, kitchen tools, etc.)

Female cooks

Both female and male in home cook

There were not many Hispanic products when first arrived but are now

8

12

6

6

2

10

II

Bought the majority of food in country of origin at:

\begin{tabular}{lcc} 
supermarkets & 5 & 28 \\
neighborhood stores & 5 & 28 \\
\hline markets & 3 & 17 \\
Bought at least some food from street markets in country of origin & 12 & 67 \\
Seasonings and herbs used in country of origin cannot be found in US & 5 & 28
\end{tabular}

Comments related to perceptions of the US food supply:

Food in US is artificia

\begin{tabular}{ll}
3 & 17 \\
\hline 4 & 22 \\
\hline 4 & 22 \\
\hline 5 & 28 \\
\hline 11 & 61
\end{tabular}

Comments related to nutrition in country of origin versus the US:

People eat healthier in US

6

6

33

People eat healthier in country of origin

II

Comments relating to factors affecting food choices:

Accessibility is the primary factor that affects food choices

Marriage to a US native influenced food choices

Hispanic family member immigrated prior to interviewee and helped learn to use food in US

Amplitude and variety of food in US affects choices

Immigrated at a young age; parents exerted strongest influence

Work schedule has an impact on food choices and preparation in US

When first arrived, tried to find the foods that were the same as home

\begin{tabular}{cc}
1 & 6 \\
\hline 1 & 6 \\
2 & 11 \\
2 & 11 \\
\hline 2 & 11 \\
7 & 39 \\
10 & 56
\end{tabular}

* Participants were asked to discuss each of the five topic areas presented above in an open ended format. Therefore, frequencies indicate the number of interviewees who made a comment related to the theme presented while discussing the particular topic area 
Table II

Selected quotes from Phase 3.

INTERVIEWEES BASED ON THEMES FROM INTERVIEWS IN THe SCott County Study, 2002

Purchase and preparation of foods

"In my country (Peru) there is not extra money for buying hamburgers. Not even a dollar. Here (in the US) a dollar is nothing*."

"When a person comes to the US, he comes with a great desire to eat. In my country (El Salvador), the possibility is not there. Here, there is the possibility of eating (i.e., food is available, but the salary is not very much*)."

"Food is artificial here. Fruits in the US do not have flavor or aroma. Milk and butter here are not milk and butter*".

Influences of food choices in the US

"In Mexico, (women) did not have to work, but here you have to work. Because of this, sometimes you have to buy easy things to give to the children. You arrive from work tired. In Mexico, you attended to your kids more. Here there is not time*."

"I look for the quickest thing... One has to work until four, five, six o'clock in the afternoon. In my country (Nicaragua), we ate three meals at specific times of day; here this has all fallen to the side because of the system of work*."

"(In my country,Argentina), I had a lot of time to dedicate to cooking, sewing, to preparing the food for the family. Here, everything has changed. Work has changed everything*".

"A person has to work twelve, fourteen, fifteen hours, not just to support his family in the US but also to send money to his home country. We do not enjoy the benefits of a citizen or resident, who has health insurance; we have to save money. The Hispanic is forced to work sixteen hours, more than normal, and this results in neglect of the family life*."

Ideas about healthy nutrition

"Poor people in my country (Honduras) cannot eat healthily."

"The diet in my country (Chile) was healthy, but you didn't think about it very much, just ate what was available. In the US people are more self-conscious about health. They tell you more about health here."

"In my country (El Salvador) there was less food, but the food we had contained more "proteins," it was more nutritious, because it was more natural*."

"In my country (Mexico) people eat what they can afford: potatoes, eggs, beans, and rice. Mexicans live off of these. Here in the US, the government helps you if you can't afford to buy your own food."

"In my country (Cuba), the people eat what they can find without thinking about if it is healthy, just to feel filled. We ate a lot of bread in my country to feel full."

(Eating healthy means) "not eating so many fried foods, eating more natural (foods), roasted or grilled meat, fish, natural potatoes*."

"Here it is expensive to eat healthy; the cheap foods make a person get fat*."

School food and children

"My children are more accustomed to eating healthy things more than the children from here. I try to prepare something healthy at night because my kids eat poorly at school. Yes, my kids prefer "chatarra" (trash), but at home I control it; I don't let them eat it*."

"Kids aren't eating their school lunches, and I think it is because snacks are sold. If they were eliminated, kids would eat the food."

* Indicates response was translated from Spanish
COMPARISON OF FOODS EATEN PRIOR TO IMMIGRATION AND After immigration IN the Scott County study, $2002(N=18)$

\begin{tabular}{|c|c|c|c|c|c|}
\hline & $\begin{array}{c}\text { Eat more } \\
\text { in US than } \\
\text { in country } \\
\text { of origin }\end{array}$ & $\begin{array}{c}\text { Ate } \\
\text { more in } \\
\text { country } \\
\text { of origin }\end{array}$ & $\begin{array}{l}\text { Eat equal } \\
\text { amount in US } \\
\text { as in country } \\
\text { of origin }\end{array}$ & $\begin{array}{l}\text { Do not } \\
\text { eat the } \\
\text { food }\end{array}$ & $\begin{array}{l}\text { Eat } \\
\text { very } \\
\text { little }\end{array}$ \\
\hline Fruits & $7(4 \mid \%)$ & $7(4 \mid \%)$ & $2(12 \%)$ & 0 & I (6\%) \\
\hline Vegetables & $7(41 \%)$ & $4(24 \%)$ & $6(35 \%)$ & 0 & 0 \\
\hline Milk and cheese & $6(35 \%)$ & $2(12 \%)$ & $8(47 \%)$ & 0 & I (6\%) \\
\hline Beef & $5(29 \%)$ & $4(24 \%)$ & $7(4 \mid \%)$ & 0 & I (6\%) \\
\hline Pork & $8(47 \%)$ & $3(18 \%)$ & $2(12 \%)$ & I (6\%) & $3(18 \%)$ \\
\hline Chicken & $9(53 \%)$ & $2(12 \%)$ & $6(35 \%)$ & 0 & 0 \\
\hline Fish & $3(18 \%)$ & $9(53 \%)$ & $2(12 \%)$ & 0 & $3(18 \%)$ \\
\hline Seafood & $3(18 \%)$ & $8(47 \%)$ & $2(12 \%)$ & 0 & $4(24 \%)$ \\
\hline Bread & $4(24 \%)$ & $8(47 \%)$ & $4(24 \%)$ & 0 & 0 \\
\hline Rice & $4(24 \%)$ & $3(18 \%)$ & $10(59 \%)$ & 0 & 0 \\
\hline Corn & $5(29 \%)$ & $9(53 \%)$ & $3(18 \%)$ & 0 & 0 \\
\hline Potatoes & $4(24 \%)$ & $3(18 \%)$ & $10(59 \%)$ & 0 & 0 \\
\hline Sweet potatoes & $4(24 \%)$ & $2(12 \%)$ & $3(18 \%)$ & $6(35 \%)$ & 0 \\
\hline Pasta & $6(35 \%)$ & I (6\%) & $6(35 \%)$ & 0 & $3(18 \%)$ \\
\hline Tortillas & $3(18 \%)$ & $6(35 \%)$ & $2(12 \%)$ & $5(29 \%)$ & I (6\%) \\
\hline Beans & I (6\%) & $3(18 \%)$ & $8(47 \%)$ & $2(12 \%)$ & $3(18 \%)$ \\
\hline Eggs & I (6\%) & $3(18 \%)$ & $12(7 \mid \%)$ & 0 & I (6\%) \\
\hline Beer & $2(12 \%)$ & I (6\%) & 0 & $9(53 \%)$ & $5(29 \%)$ \\
\hline Hamburgers & $10(59 \%)$ & 0 & I (6\%) & $2(12 \%)$ & $3(18 \%)$ \\
\hline Pizza & $10(59 \%)$ & 0 & $2(12 \%)$ & $2(12 \%)$ & $2(12 \%)$ \\
\hline
\end{tabular}

\section{Phase 4: Interpretation of data}

A meeting was held after interviews had been reviewed and responses had been recorded into tables to discuss the implications and validity of the responses with two Hispanics who had been involved in more than one phase of the project. They were presented with tables summarizing responses from the community representatives, responses from the focus group, and responses from Hispanic immigrants in the Phase 3 interviews. The reviewers agreed that work and time were in fact the most influential factors related to food choices of immigrants, and cultural awareness is needed in the community.

\section{Phase 5: Final report to the participants}

A meeting was held in December 2002 to share study findings with participants and to ascertain if they believed the translation and interpretation to be accurate. Those who attended the meeting expressed they be- 
lieved the results to be an accurate representation of the experiences of Hispanics in Scott County.

\section{Discussion}

Many factors influence dietary changes immigrants experience upon arrival in the US. Immigrants who arrive lacking the necessary skills for participation in the new cultural environment or sufficient social support for learning how to adapt to the new culture face many challenges. ${ }^{23}$ Hispanics in the US experience high rates of poverty, and newly-arrived immigrants, particularly from the Dominican Republic, Mexico, and Puerto Rico, are almost always less educated. ${ }^{24} \mathrm{Al}-$ though Hispanics come to the US with a strong work ethic, they face barriers to earning enough money to escape poverty. They are concentrated in low paying jobs with few worker protections and limited availability of health insurance. ${ }^{24}$ According to the participants in the present study, social phenomena such as these affect dietary acculturation. Although community representatives identified services available to newly-arrived immigrants, work demands diminish the possible benefits Hispanics receive from these services. The nutrition and health status of the immigrants and their descendants are influenced by the challenges they face.

\section{Factors influencing changes in food choices}

Although the factors of food cost and availability influenced research participants, work and time demands appeared to have a stronger influence on food choices. Work ethic is a strong cultural value in the US, and Hispanic labor, productivity, and buying power contribute to the success of many American industries and to the US economy. ${ }^{25}$ Changes in work demands among Hispanics affect time for meal preparation and time to enjoy meals as a family, and convenience foods often gain importance. ${ }^{26}$

Some immigrants experience a change in social environment upon relocating to the US that mirrors several decades of change in US society: increasing importance of work and decreasing time spent preparing food. ${ }^{26}$ Even though Americans are receiving more nutrition-related health information than in the past and express concern about health, intake of salt, fat, cholesterol, etc., Americans as a whole are only eating healthier if it is convenient and if it tastes good. ${ }^{27}$ In the same manner, simply providing new immigrants with nutrition information is not enough to support healthy eating habits, since time and work demands appear to be the primary influences in food choices.

\section{Dietary patterns}

Several staple foods such as eggs, rice, and potatoes showed the most stability when consumption patterns pre- and post-immigration were compared, while meats and "American foods," such as hamburgers and pizza, showed the greatest increase. According to the Food Marketing Institute, ${ }^{28}$ Hispanics exhibit a strong tie to traditional dishes, appreciate foods prepared from scratch, and consider it important to pass on the preparation of traditional dishes to their offspring. This was evident in the Scott County study; most interviewees continue to prepare traditional dishes, and several expressed preference for "comida casera" (home-cooked foods). However, several parents expressed their children were beginning to prefer "American" foods, even though they continue to prepare traditional dishes.

Processed foods may have appeal to new immigrants beyond that of reduced preparation time, since "American" foods are identified with the culture of this country, and immigrants (particularly children) may desire to become part of the new culture. Additionally, processed foods are associated with a degree of status among certain audiences, and this may increase the desirability of such foods. ${ }^{29}$ According to Uauy et al. (2001), as countries emerge from poverty, trends of increased obesity are being observed; low-income groups tend to purchase more high-fat/high-carbohydrate, energy dense foods as income increases, and sedentary habits often ensue. Thus, immigrants may have experienced the increased availability of convenience and processed foods prior to immigrating to the US. It is certain that dietary change is influenced by many factors and does not always follow a linear pattern. Dietary change is a complex process, and the preferences of the interviewees and their children will probably continue to change.

\section{Nutrition-related health concerns}

Further efforts to investigate sociocultural factors influencing acculturation, nutrition, and nutrition-related chronic disease are warranted. Although research suggests a positive relationship between acculturation and obesity among US Hispanics, ${ }^{30}$ existing studies suggest that generation alone does not determine health status; English speaking ability and income (SES) are stronger predictors. Integration into the US may be a factor that promotes health and nutrition. ${ }^{31}$

Efforts to promote nutrition should target both individual choice and the social/environmental influences of food selection. The school system is an institution with great potential for promoting individual 
and societal changes. Parents in this study voiced concern about foods consumed at school. Participants claimed pizza and hamburgers were often served for lunch, and although healthy items such as salads are offered, children do not often choose such items. The services which should be offered in schools include: "effective education in foods and nutrition; a school environment that provides opportunity and reinforcement for healthful eating and physical activity; involvement of parents and the community, and screening, counseling, and referral for nutrition problems as part of school health services." ${ }^{32}$ Schools should place higher priority on influencing food pattern development in children, and efforts to involve the family and community in promoting healthy nutrition should be made.

Although the period of time participants in the current study have spent in the US varies greatly, among other differences, similarities among participants were evident. Since Scott County does not have a long history of ethnic presence, many Hispanic immigrants in this area share commonalities with each other to a greater degree than with other residents of Scott County. Most salient is the common love for sharing food-related culture with each other and even with outsiders who show interest in learning about their culture. This commonality should be strongly considered in formulating interventions among members of this population.

\section{Application}

An intervention should be formulated to emphasize ways nutrition can be improved, taking into consideration the work and priorities of immigrants. To build confidence in the community and among individuals, efforts should be simple and achievable. Both social and individual contributions should be addressed. As previously discussed, schools have a primary role in addressing nutrition concerns. ${ }^{32}$ Since immigrants spend such a great deal of time at work and are highly influenced by this, employers should consider their role in promoting the health of their employees, through offering employee education programs, time for learning English onsite, etc.

A plan for promoting community building and nutrition in Scott County could appeal to the enjoyment of social interactions many Hispanics have by offering cross cultural cooking classes involving Hispanic and native families. The enthusiasm for cultural foods expressed by participants suggests that many Hispanics in Scott County enjoy sharing their heritage and are proud of the foods that represent their native cuisines. Again, this appears to be a commonality among Hispanics in this study, regardless of demographic differences and whether they have recently immigrated or have been in the US for many years. Cross-cultural cooking classes could allow participants of similar cultural backgrounds to jointly teach preparation of a popular native dish. A second phase could include classes to address needs identified by participants: the ingredients they use, the kinds of foods they like to prepare or would like to learn to prepare, and nutrition-related concerns. Citizen families could be invited to participate and could help newcomers learn about community resources and American culture. Newcomers could, in turn, teach natives about their own culture. This could increase cross-cultural understanding in the community.

\section{Limitations}

The Scott County study is based upon interviews with a convenience sample of 11 community representatives and 18 Hispanic immigrants, which may limit the ability to extrapolate the findings to the general population. However, an attempt was made to validate the results in several ways (as delineated above). In addition, it is not known whether the experiences voiced by these participants can be generalized to Hispanics in other rural areas in the US, though the results obtained from this study should aid in further efforts to investigate dietary effects of acculturation for US Hispanics and the development of nutrition education programs for acculturating immigrants. Also, immigrant participants in this study are extremely varied in terms of country of origin, educational background and time spent in the US, and these differences should be considered in targeting interventions. Research on changing dietary patterns of Hispanics in the US merits further investigation.

\section{Further research}

Many nutrition research efforts with the Hispanic population have investigated changes in consumption patterns; however, more emphasis needs to be focused on the factors that influence these changes and how acculturation interacts with dietary changes in order to provide interventions to promote the healthier nutrition of immigrants. According to Krondl \& Lau, ${ }^{33}$ insufficient understanding of the motives that precipitate food selection limits modification of food habits in an affluent society. Consideration of the motives that influence food choice allows for a more complete and realistic "standard of food needs," including physiological, cultural, and emotional factors. ${ }^{33}$ Further re- 
search should attempt to provide evidence of national, local and personal benefits of promoting nutrition of newcomers. Such efforts should not simply focus on changes in diet but on the multitude of social factors that precipitate those changes. Furthermore, nutrition-related interventions targeted to immigrants should be evaluated for social and cultural relevance. The importance of such evaluation is particularly salient in rural areas with relatively new ethnic presence, where resources may limit targeting specific programs for immigrants of different backgrounds.

\section{References}

I. Kittler PG, Sucher K. Food and Culture. 3rd Edition. Belmont ,CA: Wadsworth Thomson Learning, $200 \mathrm{I}$.

2. Bermudez OI, Falcon LM, Tucker KL. Intake and food sources of macronutrients among older Hispanic adults: Association with ethnicity, acculturation, and length of residence in the United States. J Am Diet Assoc 2000;100:665-673.

3. Popkin BM, Udry JR. Adolescent obesity increases significantly in second and third generation US immigrants: The national longitudinal study of adolescent health. J Nutr 1998; 128:701-706.

4. Alvarez RR. Changing patterns of family and ideology among Latino cultures in the United States. In:Weaver,T. Kanellos N, Esteva-Fabregat C, ed. Handbook of Hispanic Cultures in the United States. Houston, Texas: Arte Público Press, 1994:147-166.

5. Schmidley AD. Profile of the foreign born population in the United States: 2000. Current Population Reports, Series P23-206. Washington, DC: United States Census Bureau, 200I.

6. Guzman B. The Hispanic Population 2000. Census 2000 Brief. U.S. Life, Census Bureau. Available at: http://www.census.gov

7. Hernández-León R, Zuniga V. Social capital of Mexican communities in the South. Southern Perspectives 2002;6: I-4.

8. Erwin DO. Latino immigration to Arkansas: Saints and salsa meet poultry and Protestants. Southern Perspectives 2002;6:4-6.

9. Atiles JH, Bohon S. Camas calientes. Southern Perspectives 2002;6:6-7. 10. National Center for Health Statistics. Healthy People 2000 Review 1997. Hyattsville, MD: Public Health Service, 1997.

II. Carrasquillo O, Himmelstein DU,Woolhandler S, Bor D. Trends in health insurance coverage, 1989-1997. Int J Health Serv 1999;29:467-483. 12. Gans KM, Lovell HJ, Fortunet R, McMahon C, Carton-Lopez S, Lasater TM. Implications of a qualitative research for nutrition education geared to selected Hispanic audiences. J Nutr Educ 1999;31:331-338.

13. Romero-Gwynn EU, Gwynn D. Food and dietary adaptations among Hispanics in the United States. In:Weaver T, Kanellos N, Esteva-Fabregat C, ed. Handbook of Hispanic Cultures in the United States:Anthropology. Houston, Texas: Arte Público Press, 1994: 339-366.

14. Kuczmarski MF, Kuczmarski RJ, Najjar MN. Food usage among Mexican-American, Cuban, and Puerto Rican adults: Findings from the Hispanic HANES. Nutr Today 1995;30:30-37.
15. United States Census Bureau. (2003, July 15). State and County QuickFacts. Accessed on 2003 October 15, Available at: http:// quickfacts.census.gov/qfd/states/28/28I23.html.

16. Shepherd SK, Achterberg C L. Qualitative research methodology: Data collection, analysis, interpretation, and verification. In: Monsen E, ed. Research: Successful Approaches. Chicago, Illinois: American Dietetic Association, 1992:82-99.

17. Suarez-Balcazar Y, Balcazar F, Quiros M, Chavez M, Quiros O.A case study of international cooperation for community development and primary prevention in Costa Rica. Prev Hum Serv 1995; 12:3-23. 18. Clark J, Hoffman CJ. Recursos en Español: Suggestions for meeting the health and nutrition education needs of Hispanic and immigrant families. Topics in Clinical Nutrition 1998;13:73-82.

19. Hampl JS. Focus groups indicate that vegetable and fruit consumption by food stamp-eligible Hispanics is affected by children and unfamiliarity with non-traditional foods. J Am Diet Assoc 2001;101:685-687.

20. Romero-Gwynn E, Gwynn D, Lopez M, Turner B,Asarian-Anderson J, Daud M. Dietary patterns and acculturation among immigrants from El Salvador. Nutr Today 2000;35:233-242.

21. Carbone ET, Campbell MK, Honness-Morreale L. Use of cognitive interview techniques in the development of nutrition surveys and interactive nutrition messages for low-income populations. J Am Diet Assoc 2002; 102:690-696.

22. Kondracki NL, Wellman NS, Amundson, DR. Content analysis: Review of methods and their applications in nutrition education. J Nutr Educ Behav 2002;34:224-230.

23. Dressler WW, Bernal H. Acculturation and stress in a low-income Puerto Rican community. J Human Stress 1982;8:32-38.

24. Hernandez R, Siles, M, Rochín RI. Latino Youth: Converting challenges to opportunities. JSRI Working Paper No. 50. East Lansing, Ml:The Julian Samora Research Institute, Michigan State University, 200I.

25. Perez S. Beyond the Census: Hispanics and an American agenda. Washington, DC: National Council of La Raza, 200I.

26. Krondl M, Lau D. Social determinants in human food selection. In: Barker L, ed. The Psychobiology of Human Food Selection. Westport, Connecticut: AVI Publishing Company, 1982:139-15I.

27. Kara A, Kaynak E, Kucukemiroglu O. Marketing strategies for fast food restaurants: A consumer's view. Br Food J 1997;99:318-324. 28. Hollingsworth P. Hispanic market shows huge potential. Food Technology 2003;57:26-30.

29. Uauy R, Albala C, Kain J. Obesity trends in Latin America:Transiting from under- to overweight.J Nutr 200I;131:893S-899S.

30. Khan LK, Sobal J, Martorell R. Acculturation, socioeconomic status, and obesity in Mexican Americans, Cuban Americans, and Puerto Ricans. Int J Obes Relat Metab Disord 1997;21:91-96.

31. Sundquist J,Winkleby MA. Cardiovasuclar risk factors in Mexican American adults: A Transcultural analysis of NHANES III, 1988-1994. Am J Public Health 1999;89:723-730.

32. American Dietetic Association. School-based nutrition programs and services- Position of the ADA, SNE, and ASFDA. J Am Diet Assoc 1995;95:367-369.

33. Krondl M, Lau D. Food habit modification as a public health measure. C J Public Health 1978;69:39-48. 